\title{
Batch-Injection Amperometric Determination of Pyrogallol in Biodiesel Using a Multi-Walled Carbon Nanotube Modified Electrode
}

\author{
Rafael M. Cardoso, Rafael M. Dornellas, Ana P. Lima, Rodrigo H. O. Montes, \\ Eduardo M. Richter and Rodrigo A. A. Munoz*
}

Instituto de Química, Universidade Federal de Uberlândia, Av. João Naves de Ávila, 2121, 38408-100 Uberlândia-MG, Brazil

\begin{abstract}
This work demonstrates the application of batch-injection analysis (BIA) with amperometric detection on a multi-walled carbon nanotube (MWCNT) modified electrode for the sensitive determination of the antioxidant pyrogallol in biodiesel. Samples were diluted in electrolyte $\left(0.1 \mathrm{~mol} \mathrm{~L}^{-1} \mathrm{HClO}_{4}\right)$ before injection using an electronic micropipette on the BIA cell. The size effect of MWCNTs on electrochemical oxidation of pyrogallol was investigated and 3.5-fold increase in the amperometric sensitivity using the modified electrode with MWCNTs of shorter dimensions was obtained. This result was in agreement with cyclic voltammetry and electrochemical impedance spectroscopy measurements. After optimization of BIA parameters for the amperometric detection on the MWCNT-modified electrode, the proposed method presented a linear range from 0.3 to $1000 \mu \mathrm{mol} \mathrm{L}{ }^{-1}$, detection limit of $0.013 \mu \mathrm{mol} \mathrm{L}-1$, precision of $3 \%$, and sample throughput of $240 \mathrm{~h}^{-1}$. Spiked biodiesel samples were analyzed and recovery values between $95-99 \%$ were obtained.
\end{abstract}

Keywords: amperometry, biofuel, carbon nanotubes, electrocatalysis, phenolic compounds

\section{Introduction}

Biodiesel is a renewable fuel widely consumed worldwide. Due to the similar physical-chemistry characteristics to diesel oil and to reduce environment pollution from fossil fuels, the introduction of biodiesel in the market has been accelerated. ${ }^{1}$ However, the negative point of biodiesel is its lower oxidation stability. For this reason, antioxidants are added to this biofuel to increase its oxidation stability and consequently to avoid technical problems related to the formation of sediments in storage tanks and inside engines. ${ }^{2,3}$ One successful antioxidant added to biodiesels is pyrogallol, 1,2,3-trihydroxybenzene, as previous works have demonstrated. ${ }^{2,47}$ Therefore, the monitoring of this antioxidant in biodiesel can bring information related to the oxidation stability of biodiesels. ${ }^{8}$

Electrochemical methods have been reported to the determination of pyrogallol (PY), including enzyme electrodes system, ${ }^{9}$ screen-printed graphite electrodes, ${ }^{10,11}$ modified carbon paste electrodes, ${ }^{12,13}$ and polyaminoanthraquinone film-modified platinum wire, ${ }^{14}$ which were applied to different matrices. Only one of these works was devoted to the analysis of biodiesel. ${ }^{10}$

*e-mail: munoz@ufu.br
The main drawback of the analysis of biodiesel by electrochemical methods is related to the low dielectric constant of this matrix, adsorption effects on the electrode surface and incompatibility with screen-printed electrodes..$^{15-17}$ Because of this difficulty, sample dilution in hydroethanolic electrolyte is often necessary to the analysis of biodiesel. ${ }^{10,16,17}$

Electrodes modified with carbon nanotubes (CNTs) are widely used because they have important characteristics such as high electron transfer due to its electrocatalytic capacity, high resistance to surface fouling, greater active area, resulting in improved electrochemical sensors with higher sensitivity. ${ }^{18-20} \mathrm{CNTs}$ are designated into two classes: single-walled carbon nanotubes (SWCNT), with a single rolled graphene sheet; and multi-walled carbon nanotubes (MWCNT) with a set of rolled graphene sheets spaced between their layers. Some factors are assigned to the electrocatalytic effect of CNTs, as the presence of defect regions in the tubes and edge-plane-like sites. ${ }^{21,22}$ Metallic impurities can also contribute for these electrocatalytic effects. ${ }^{23,24}$ A glassy-carbon electrode (GCE) modified with CNTs was evaluated for the voltammetric detection of water-soluble antioxidants, including PY, with improved detection limits and larger linear range due to the chemical modifier. $^{25}$ 
The objective of this study is to determine PY in biodiesel samples using batch-injection analysis (BIA) with amperometric detection and a GCE modified with MWCNTs. Two different sizes (D $\times$ L: 100-170 $\mathrm{nm} \times 5-9 \mu \mathrm{m}$ and 6-9 $\mathrm{nm} \times 5 \mu \mathrm{m}$, corresponding to LD- (larger diameter) and SD- (smaller diameter) MWCNTs, respectively) of MWCNTs were compared to the determination of PY based on the analytical response of the sensor.

\section{Experimental}

\section{Materials}

MWCNTs of two different sizes $(D \times L$ : 100-170 $\mathrm{nm} \times 5-9 \mu \mathrm{m}$ and 6-9 $\mathrm{nm} \times 5 \mu \mathrm{m}$, corresponding to LD- and SD-MWCNTs, respectively) were used in this work to modify the GCE surface. MWCNTs and pyrogallol (<99 wt.\%) were obtained from Aldrich (Milwaukee, WI, USA).

A water purification system Milli-Q (Millipore, Bedford, MA, USA) was used for the deionized water (resistivity of no less than $18 \mathrm{M} \Omega \mathrm{cm}$ ) utilized to prepare the solutions. The stock solution of PY in the concentration of $10 \mathrm{mmol} \mathrm{L}^{-1}$ was prepared in the supporting electrolyte $\left(0.1 \mathrm{~mol} \mathrm{~L}^{-1}\right.$ $\mathrm{HClO}_{4}$ from Reagen (Rio de Janeiro, Brazil)) daily before experiments were performed. Dispersions of carbon nanotubes were prepared in dimethylformamide (DMF) at a concentration of $1 \mathrm{mg} \mathrm{mL}^{-1}$ daily and never reutilized.

\section{Apparatus}

The preparation of suspensions of MWCNTs in DMF were assisted by an ultrasonic probe Cole-Parmer, model CPX 130 (Illinois, USA) of $130 \mathrm{~W}$ and frequency of $20 \mathrm{kHz}$.

All electrochemical measurements were performed on a $\mu$-AUTOLAB Type III potentiostat (Eco Chemie, Utrecht, Netherlands) coupled to a computer with NOVA software 1.11 for data acquisition and instrument control. The voltammetric analyzes were performed on a $10 \mathrm{~mL}$ beaker and amperometric tests were performed coupled to the BIA system. The working electrode, modified or unmodified, was a glassy carbon disc $(\varnothing=1.5 \mathrm{~mm}$, Basi Inc., USA), a platinum wire was used as counter electrode, and a miniaturized $\mathrm{Ag} / \mathrm{AgCl} /$ saturated $\mathrm{KCl}$ electrode ${ }^{26}$ was used as reference electrode.

\section{MWCNT functionalization}

The functionalization with carboxyl groups of MWCNTs was made by adding $1 \mathrm{~g}$ of MWCNT in a mixture of 3:1 concentrated $\mathrm{HNO}_{3} / \mathrm{H}_{2} \mathrm{SO}_{4}(1000 \mathrm{~mL})$ in an ultrasonic bath for three hours at $60{ }^{\circ} \mathrm{C}$. After cooling to room temperature, suspension of functionalized MWCNTs (MWCNT-COOH) was added dropwise in $3000 \mathrm{~mL}$ of deionized water and vacuum filtered through filter paper. The material was washed with deionized water until obtaining neutral $\mathrm{pH}$. Then the sample was dried in a vacuum oven at $80{ }^{\circ} \mathrm{C}$ for 8 h. ${ }^{27}$

\section{Preparation of the MWCNT modified electrodes}

The GCE surface of the working electrode was previously been mechanically cleaned using a polishing slurry in an alumina $(0.3 \mu \mathrm{M})$ in a felt support, followed by washing with deionized water, and subsequently sonicated for $5 \mathrm{~min}$ in a $50 \%(\mathrm{v} / \mathrm{v})$ hydroethanol solution.

A suspension containing functionalized MWCNTs (1.0 $\left.\mathrm{mg} \mathrm{mL}^{-1}\right)$ in DMF was sonicated with an ultrasound probe for $15 \mathrm{~min}$ under high frequency pulse (pulse of $5 \mathrm{~s}$ and $2 \mathrm{~s}$ of rest) with $35 \%$ amplitude. Subsequently, $10 \mu \mathrm{L}$ of this suspension was added on the surface of the GCE, and the electrode was placed for $30 \mathrm{~min}$ at $60{ }^{\circ} \mathrm{C}$ oven. After this period, the GCE modified with MWCNTs was washed with deionized water and an electrochemical activation was carried out with cyclic voltammetry at a potential range from 0 to $1000 \mathrm{mV}$ in a $\mathrm{HClO}_{4}$ electrolyte solution at $50 \mathrm{mV} \mathrm{s}^{-1}$ until obtaining reproducible voltammograms, which was generally obtained after five cycles.

\section{Biodiesel samples and protocol of sample preparation}

The biodiesel samples were produced from soybean, canola and cottonseed oils in laboratory free of antioxidants through a transesterification reaction with methanol and $\mathrm{KOH}$.

The antioxidant PY was added to biodiesel samples to perform the recovery tests at concentration levels of 48 and $91 \mathrm{mg} \mathrm{L}^{-1}$.

Biodiesel samples were 36-fold diluted in ethanol, followed by new dilution (10-fold) in electrolyte $\left(0.1 \mathrm{~mol} \mathrm{~L}^{-1} \mathrm{HClO}_{4}\right)$ before injection into the BIA system for the amperometric detection on the MWCNT-modified electrode, similarly to a previous work devoted to the determination of antioxidants in biodiesel. ${ }^{16}$

\section{Electrochemical measurements}

The measures of electrochemical impedance spectroscopy were all performed in a frequency range from 0.1 to $30,000 \mathrm{~Hz}$ with an amplitude of $10 \mathrm{mV}$ and 10 points per decade of frequency, in a $0.1 \mathrm{~mol} \mathrm{~L}^{-1} \mathrm{KCl}$ solution 
containing $5.5 \mathrm{mmol} \mathrm{L}^{-1} \mathrm{~K}_{3} \mathrm{Fe}(\mathrm{CN})_{6} / \mathrm{K}_{4} \mathrm{Fe}(\mathrm{CN})_{6}$. The analysis of the non-linear region of the semi-circle Nyquist plot $\left(Z_{\text {imaginary }} v s . Z_{\text {real }}\right)$ was used to obtain resistance to electron transfer. The measurements were performed in triplicate.

The initial voltammetric tests were used to obtain best working $\mathrm{pH}$ and supporting electrolyte (Britton-Robinson buffer solutions in the $\mathrm{pH}$ range between 3 and 7 and a $0.1 \mathrm{~mol} \mathrm{~L}^{-1} \mathrm{HClO}_{4}$ solution). Amperometric tests were made using an homemade BIA cell (approximately $200 \mathrm{~mL})^{28}$ equipped with an electronic micropipette (Eppendorf Multipette stream $)^{29}$ for sample injections. The micropipette tip was positioned in a wall-jet position at a fixed distance of $2 \mathrm{~mm}$ from the working electrode. The parameters such as dispensing rate and injected volume were optimized to obtain better current density, low current noise and higher signal reproducibility. The optimal injection volume and dispensing rate were $150 \mu \mathrm{L}$ and $156 \mu \mathrm{L} \mathrm{s}^{-1}$, respectively, for the determination of PY. All measurements were carried out without the removal of dissolved oxygen and at room temperature.

\section{Results and Discussion}

The supporting electrolyte for the electrochemical experiments was initially studied. The voltammetric profile of PY oxidation was evaluated by cyclic voltammetry in $0.04 \mathrm{~mol} \mathrm{~L}^{-1}$ Britton-Robinson buffer in the $\mathrm{pH}$ range between 3 and 7 and $0.1 \mathrm{~mol} \mathrm{~L}^{-1}$ perchloric acid. The $\mathrm{HClO}_{4}$ solution was chosen for further electrochemical studies of PY because well-shaped voltammetric peaks were obtained in this solution on GCE in comparison with the experiments performed in Britton-Robinson buffer solutions. This electrolyte was also used in a previous work reported in the literature ${ }^{29}$ for the determination of phenolic antioxidants, showing better performance at the concentrations prepared in this work.

Cyclic voltammetry was performed for PY $\left(1 \mathrm{mmol} \mathrm{L}^{-1}\right)$ on bare and modified GCE with MWCNTs at a scan rate of $50 \mathrm{mV} \mathrm{s}^{-1}$ (Figure 1).

Changes were observed in the electrochemical responses obtained with the different modifications of GCE with MWCNTs. The peak potential $\left(\mathrm{E}_{\mathrm{p}}\right)$ on SD-MWCNT-modified GCE $(501 \mathrm{mV})$ was slightly anticipated in comparison with the peak on the LD-MWCNT-modified GCE $(522 \mathrm{mV})$, which may indicate a possible electrocatalytic behavior of SD-MWCNTs. The peak current $I_{p}$ was slightly higher on the SD-MWCNT-modified GCE compared to the other electrodes tested. Moreover, it is noticed that the voltammetric response on both MWCNT-modified electrodes was superior in comparison with the response on the bare electrode.

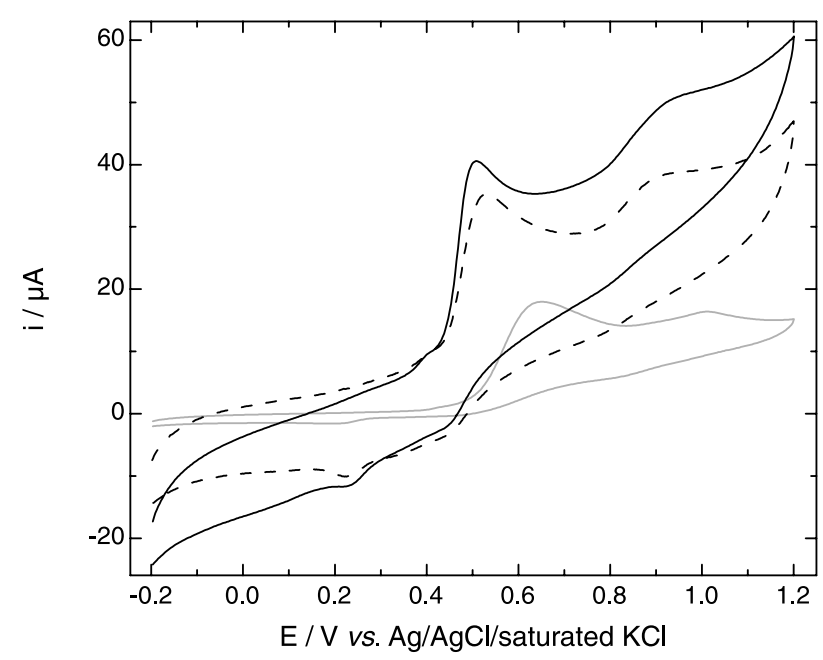

Figure 1. Cyclic voltammograms of $1 \mathrm{mmol} \mathrm{L}^{-1} \mathrm{PY}$ on unmodified GCE (-) and modified with SD-MWCNT (-) and LD-MWCNT (--) in $0.1 \mathrm{~mol} \mathrm{~L}^{-1} \mathrm{HClO}_{4}$. Scan rate $50 \mathrm{mV} \mathrm{s}^{-1}$.

Electrochemical impedance spectroscopy (EIS) was used to evaluate the characteristics of the clean and modified GCE with MWCNTs and the results obtained are recorded in Figure 2.

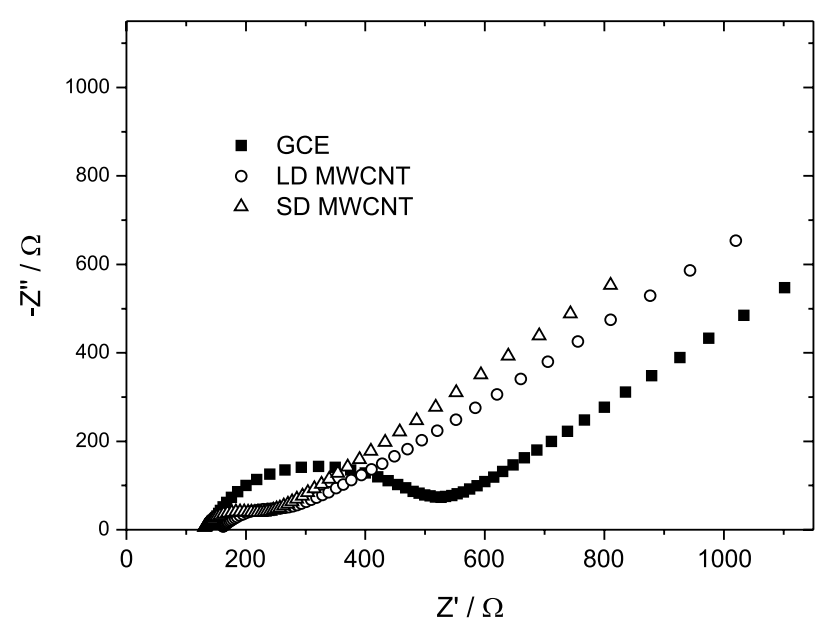

Figure 2. Nyquist plots for (ם) GCE, (O) LD-MWCNT and $(\triangle)$ SD-MWCNT $0.1 \mathrm{~mol} \mathrm{~L}^{-1} \mathrm{KCl}$ containing $5 / 5 \mathrm{mmol} \mathrm{L}^{-1}$ of $\left[\mathrm{Fe}(\mathrm{CN})_{6}\right]^{3-} /\left[\mathrm{Fe}(\mathrm{CN})_{6}\right]^{4}$.

The impedance $(\mathrm{Z})$ function is the measure of tendency of a system to resist or prevent the flow of alternating electrical current..$^{30}$ The unmodified electrode has a higher resistance to charge transfer, as evidenced by the greater portion of the semicircle Nyquist plot and larger $Z_{\text {real }}$ values. For the electrodes modified with MWCNTs, the Nyquist semicircles are smaller, offering higher electronic transfer and facilitating the occurrence of redox reaction on the surface of the working electrode. Moreover, the EIS results on the SD-MWCNT-modified GCE were better than those obtained on LD-MWCNT, due to the presence 
of minor portions of the semicircle and smaller values of $\mathrm{Z}_{\text {real }}$ both at high and low frequencies. This low impedance of MWCNTs is due to the increased conductive nature of the modified surface with nanomaterials. Furthermore, the linear portions at low frequencies showed similar intensities for all electrodes, which indicate similar diffusion effects.

The results of EIS are in agreement with those observed by cyclic voltammetry, which indicates a higher electrocatalytic activity of the SD-MWCNT-modified surface. This result is in agreement with a previous report that revealed that the electrochemical activity of MWCNTs is dependent on their dimensions, specifically the greater amount of structural defects in smaller diameter nanotubes may be responsible for the lower electronic resistance of the electrode. ${ }^{29}$ Therefore, based on the EIS measurements and cyclic voltammetric experiments, it was expected to obtain better performance on the SD-MWCNT-modified GCE towards the electrochemical oxidation of PY.

The mass transport of PY on the three electrodes was studied using cyclic voltammetry by varying the scan rate in function of the oxidation peak current. PY presented a plot with linear behavior of $\mathrm{I}_{\mathrm{p}}$ versus $\mathrm{V}^{1 / 2}$ for GCE, LD-MWCNT- and SD-MWCNT-modified GCE for the two oxidation peaks, indicating a diffusion-controlled behavior in all cases. The mechanism of electrochemical oxidation of PY involves two processes of two-electron transfer as shown in the cyclic voltammograms. Both electrochemical oxidation processes involves the formation of quinone derivatives. ${ }^{25,31}$

Amperometric tests coupled to the BIA system were carried out to evaluate the BIA parameters on the different electrodes and investigate the occurrence of possible electrocatalytic effects on the electrode surface. The BIA parameters were optimized in order to obtain the highest current intensity, lowest standard deviation, and highest analytical frequency. The optimized BIA parameters were injection volume (from 25 to $300 \mu \mathrm{L}$ ) and dispensing rate of the electronic micropipette (from 28 to $344 \mu \mathrm{L} \mathrm{s}^{-1}$ ) using the potential of $+0.6 \mathrm{~V}$ and a solution of $50 \mu \mathrm{mol} \mathrm{L}^{-1} \mathrm{PY}$. The best injection volume and dispensing rate were found to be $150 \mu \mathrm{L}$ and $156 \mu \mathrm{L} \mathrm{s}^{-1}$, respectively, based on the highest analytical response and lowest standard deviation for triplicate injections.

Hydrodynamic voltammograms were constructed for injections of $50 \mu \mathrm{mol} \mathrm{L}^{-1} \mathrm{PY}$ on unmodified and modified GCEs in the potential range from 0.2 and $1.0 \mathrm{~V}$. Figure 3 presents the plots of the average current values for the triplicate injections performed in function of the each applied potential.

The electrochemical oxidation of PY presents two oxidation peaks as shown in the cyclic voltammetric

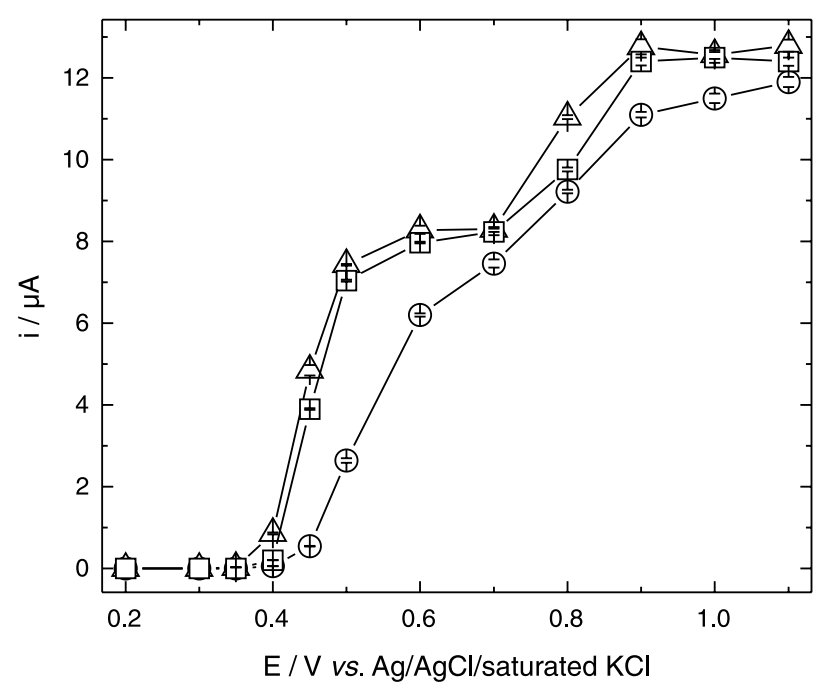

Figure 3. Hydrodynamic voltammograms ( $\mathrm{I}_{\text {peak }} v s$. E) obtained from triplicate injections at various potentials at $(\boxminus)$ SD-MWCNT-, $(\triangle)$ LD-MWCNT-modified GCE and $(\theta)$ unmodified GCE in the presence of $50 \mu \mathrm{mol} \mathrm{L} \mathrm{L}^{-1}$ of PY. BIA parameters: $150 \mu \mathrm{L}$ as injection volume at $156 \mu \mathrm{L} \mathrm{s}^{-1}$ of dispensing rate with $0.1 \mathrm{~mol} \mathrm{~L}^{-1} \mathrm{HClO}_{4}$ supporting electrolyte.

experiments, and the electrodes modified with SD and LD-MWCNTs showed quite similar results as shown in Figure 3. The plots show a gain of approximately $1.8 \mu \mathrm{A}$ at the first oxidation potential (29\% gain) and $1.3 \mu \mathrm{A}(11 \%$ gain) at the second potential and peak anticipation of about $50 \mathrm{mV}$ on both MWCNT-modified GCEs in comparison with the bare GCE.

Two applied potentials $(+0.5$ to $+0.9 \mathrm{~V})$ were chosen from the results obtained in the hydrodynamic voltammograms and used to investigate the analytical linear range using the three different electrodes. The linear range initially studied ranged from 1 to $1000 \mu \mathrm{mol} \mathrm{L}^{-1} \mathrm{PY}$ and the parameters evaluated were sensitivity (slope of the curves), correlation coefficient $\left(\mathrm{R}^{2}\right)$, and limits of detection (LOD) and quantification (LOQ). The obtained linear ranges are shown in Figure 4.

Figure 4A illustrates the analytical curves obtained on the three electrodes under the application of $+0.5 \mathrm{~V}$. All curves presented similar linear ranges $\left(1-1000 \mu \mathrm{mol} \mathrm{L}^{-1}\right)$, but with different sensitivities. The curve using GCE electrode modified with SD-MWCNT has higher peak currents and consequently higher sensitivity than the ones obtained on bare and LD-MWCNT-modified GCE. The electrode containing LD-MWCNT also showed sensitivity improvement over GCE under the application of $+0.5 \mathrm{~V}$. These results indicate that the improved sensitivity of the SD-MWCNT-modified electrode can be due to the enhanced electrochemical activity of this electrode as stated before in this paper. On the other hand, when $+0.9 \mathrm{~V}$ was applied for PY detection 
(Figure 4B), the curves also showed similar linear ranges (1-1000 $\left.\mu \mathrm{mol} \mathrm{L}^{-1}\right)$, but a slight improvement on the slope values was observed for SD and LD-MWCNT-modified
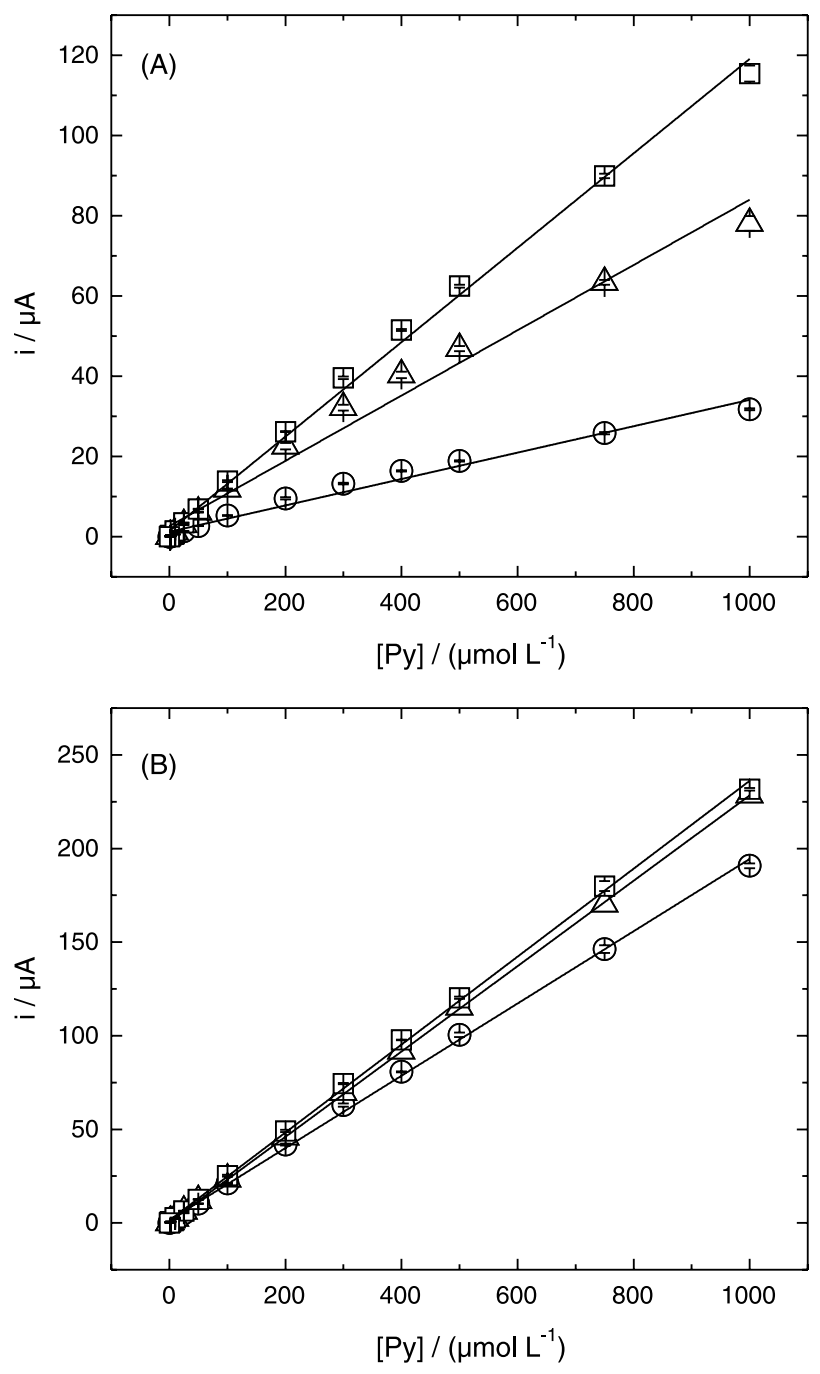

Figure 4. Analytical curves obtained under the application of (A) $+0.5 \mathrm{~V}$ and (B) $+0.9 \mathrm{~V}$ (linear range 1-1000 $\mu \mathrm{mol} \mathrm{L}^{-1}$ ) on ( $\boxminus$ ) SD-MWCNT, $(\triangle)$ LD-MWCNT modified GCE and $(\ominus)$ unmodified GCE using a BIA cell $\left(150 \mu \mathrm{L}\right.$ injection at $156 \mu \mathrm{L} \mathrm{s}^{-1}$ of dispensing rate with $0.1 \mathrm{~mol} \mathrm{~L}^{-1}$ $\mathrm{HClO}_{4}$ as supporting electrolyte).
GCE in relation to GCE. The improved performance of SD-MWCNT-modified GCE was not highlighted as before demonstrated. However, there is an increase in sensitivity when comparing the results obtained at $+0.5 \mathrm{~V}$ with the ones obtained at $+0.9 \mathrm{~V}$, which is probably due to the contribution of the second electron transfer process that is in agreement with the hydrodynamic voltammograms for PY (Figure 3). Therefore, the applied potential of $+0.9 \mathrm{~V}$ was selected for further amperometric measurements although, under this condition, the sensitivity of the SD-MWCNT-modified electrode was not significantly higher than the one obtained with LD-MWCNT-modified GCE. A similar result was verified in a previous study of the amperometric determination of phenolic compounds when a more positive potential was applied..$^{29}$

A repeatability study was performed by calculating the relative standard deviation (RSD) of 20 consecutive measurements of the lower concentration of the calibration curve in the two applied potentials using bare and GCE modified with MWCNTs. Table 1 shows that a lower RSD value was obtained for the SD-MWCNT-modified electrode with a value of $2.9 \%$ while values higher than $5 \%$ were obtained for GCE and LD-MWCNT-modified GCE when the potential of $+0.5 \mathrm{~V}$ was applied for the detection of PY. However, RSD values lower than 5\% for the three electrodes were obtained when the potential of $+0.9 \mathrm{~V}$ was applied. These results indicate that the electrodes are more stable under the application of higher potentials. The response times of the electrodes were compared and these values used to calculate theoretical analytical frequency (AF) values (Table 1). The average response time $(n=20)$ was obtained from amperometric measurements by calculating the average time of transient peaks. The number of peaks that could be registered in $1 \mathrm{~h}$ results in the theoretical AF value $\left(\right.$ in $\left.\mathrm{h}^{-1}\right)$. Table 1 shows that the AF values were higher on the modified electrodes as a result of the fast responses for PY, which is an indicative of the higher electron transfer kinetics caused by MWCNTs.

Table 1. Analytical curve data (slope and correlation coefficient) in the range of 1 and $1000 \mu \mathrm{mol} \mathrm{L}^{-1}$, relative standard deviation $(\mathrm{RSD})$ for $\mathrm{n}=20$, and theoretical analytical frequency (AF) obtained from amperometric recordings for PY at unmodified and modified GCE with SD-MWCNT and LD-MWCNT using a BIA cell

\begin{tabular}{|c|c|c|c|c|}
\hline & Slope / $\left(\mu \mathrm{A} \mu \mathrm{mol}^{-1} \mathrm{~L}\right)$ & $\mathrm{RSD} / \%$ & $\mathrm{AF} / \mathrm{h}^{-1}$ & $\mathrm{R}^{2}$ \\
\hline \multicolumn{5}{|c|}{ Applied potential: $+0.5 \mathrm{~V}$} \\
\hline GCE & 0.033 & 7.9 & 596 & 0.980 \\
\hline LD-MWCNT & 0.081 & 10.9 & 890 & 0.981 \\
\hline SD-MWNCT & 0.117 & 2.9 & 988 & 0.997 \\
\hline \multicolumn{5}{|c|}{ Applied potential: $+0.9 \mathrm{~V}$} \\
\hline GCE & 0.193 & 3.1 & 839 & 0.999 \\
\hline LD-MWCNT & 0.228 & 1.5 & 1078 & 0.999 \\
\hline SD-MWNCT & 0.235 & 3.0 & 882 & 0.999 \\
\hline
\end{tabular}

GCE: glassy-carbon electrode; LD-MWCNT: larger diameter multi-walled carbon nanotube; SD-MWCNT: smaller diameter-MWCNT. 
Table 2. Recovery values obtained by the proposed method for the analysis of biodiesels samples

\begin{tabular}{lcccccc}
\hline Biodiesel & Added / $\left(\mathrm{mg} \mathrm{L}^{-1}\right)$ & Found / $\left(\mathrm{mg} \mathrm{L}^{-1}\right)$ & Recovered / $\%$ & Added / $\left(\mathrm{mg} \mathrm{L}^{-1}\right)$ & Found / $\left(\mathrm{mg} \mathrm{L}^{-1}\right)$ & Recovered / \% \\
\hline Cotton & 91 & $90 \pm 2$ & $99 \pm 2$ & 48 & $45 \pm 1$ & $95 \pm 2$ \\
Canola & 91 & $90 \pm 6$ & $99 \pm 5$ & 48 & $45 \pm 2$ & $95 \pm 4$ \\
Soybean & 91 & $90 \pm 2$ & $99 \pm 2$ & 48 & $46 \pm 2$ & $96 \pm 4$ \\
\hline
\end{tabular}

Considering the time used to refill the BIA micropipette with standard solutions, the real analytical frequency was estimated in $240 \mathrm{~h}^{-1}$, much lower than the theoretical values in Table 1 . Yet the analytical frequency is significantly high comparing with previous works using amperometric detection on MWCNT-modified electrodes. ${ }^{32,33}$

The method developed by BIA with amperometric detection was used to determine PY in three different types of biodiesel (obtained from cottonseed, rapeseed and soybean oils) fortified in two concentration levels of (48 and $\left.91 \mathrm{mg} \mathrm{L}^{-1}\right)$. Recovery tests were performed at $+0.9 \mathrm{~V}$ using the electrode modified with SD-MWCNTs due to the higher sensitivity of this electrode for the detection of PY. Biodiesel samples required dilution prior injection due to immiscibility of biodiesel and aqueous electrolyte. A 360-fold dilution was optimized in order to obtain a stable microemulsion of biodiesel in water/ethanol solution as previously demonstrated. ${ }^{34}$ Due to the high dilution rate, the modified electrode was explored in concentrations lower than $1 \mu \mathrm{mol} \mathrm{L} \mathrm{L}^{-1}$. Figure 5 shows an amperometric recording for an analytical curve obtained with PY concentrations

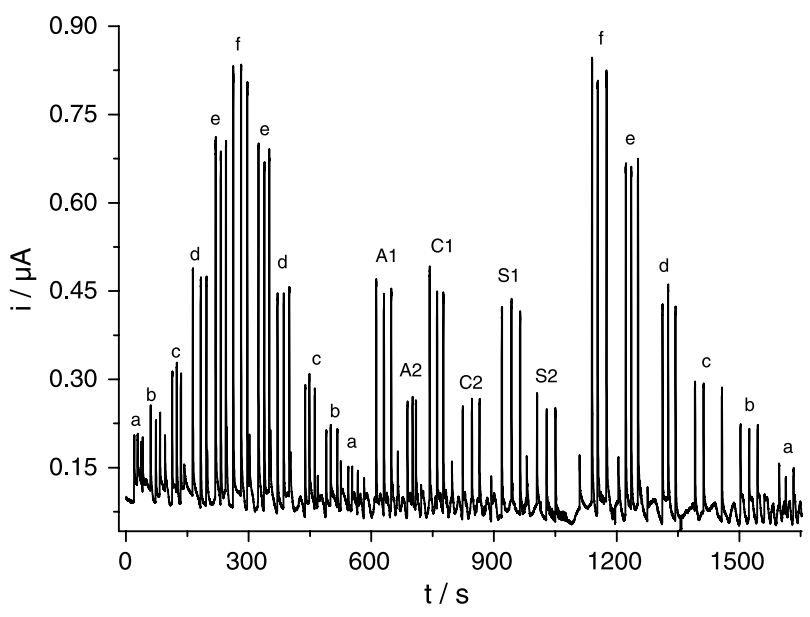

Figure 5. Amperogram for biodiesel analysis (recovery test) obtained by BIA with amperometric detection at $+0.9 \mathrm{~V}$ using the SD-MWCNT-modified GCE: injections in triplicate of (a) 0.4, (b) 0.8, (c) 1.2 , (d) 2.0 , (e) 3.2 , and (f) $4.0 \mu \mathrm{mol} \mathrm{L} \mathrm{L}^{-1} \mathrm{PY}$ (that corresponds to $0.05,0.1,0.15,0.25,0.40$, and $0.50 \mathrm{mg} \mathrm{L}^{-1}$, respectively) and samples of biodiesel at two doping levels, 91 and $48 \mathrm{mg} \mathrm{L}^{-1}$ (that corresponds to 0.25 and $0.12 \mathrm{mg} \mathrm{L}^{-1}$ in the curve after 360-fold dilution) for biodiesels obtained from cottonseed (A1,A2); canola (C1, C2) and soybean (S1, S2) oils. BIA parameters: $150 \mu \mathrm{L}$ injection volume at $156 \mu \mathrm{L} \mathrm{s}^{-1}$ of dispensing rate using $0.1 \mathrm{~mol} \mathrm{~L}^{-1} \mathrm{HClO}_{4}$ as supporting electrolyte. between 0.4 and $4.0 \mu \mathrm{mol} \mathrm{L} \mathrm{L}^{-1}$ for increasing and decreasing concentrations. After that, diluted biodiesel samples were injected (spiked with PY at two concentration levels as biodiesel samples were free of antioxidants including PY). Finally, the standard solution of PY was injected in the same amperometric recording as shown in Figure 5. This section of injections shows that no carryover effects were verified even after injection of biodiesel samples.

The method presented satisfactory accuracy for PY determination in biodiesel samples from three different matrices with recovery values over $95 \%$ for both fortification levels as shown in Table 2. The LOD of the method using SD-MWCNT-modified GCE was calculated for 3 times the standard deviation of 10 consecutive measurements of lower concentrations of the calibration curve, divided by the slope of the calibration curve. The LOD value was estimated in $0.013 \mu \mathrm{mol} \mathrm{L}^{-1}$ (corresponds to $0.002 \mathrm{mg} \mathrm{L}^{-1}$ ).

\section{Conclusions}

This work demonstrates the improved performance of MWCNT-modified electrodes for the sensitive detection of the antioxidant PY. Lower dimension MWCNTs provided superior electrochemical activity towards PY detection, which was in agreement with EIS measurements. The modified electrode was successfully coupled to a BIA cell to carry out amperometric determinations of PY in biodiesel samples. The accuracy of the proposed method was attested by recovery values within acceptable results (>95\%).

\section{Acknowledgments}

The authors are grateful to FAPEMIG (PPM-00640-16) and CAPES for financial support. R. M. D., E. M. R., and R. A. A. also thank to CNPq for the respective fellowships.

\section{References}

1. Stamenković, O. S.; Veličković, A. V.; Veljković, V. B.; Fuel 2011, 90, 3141.

2. Jain, S.; Sharma, M. P.; Renewable Sustainable Energy Rev. 2010, 14, 667. 
3. Domingos, A. K.; Saad, E. B.; Vechiatto, W. W. D.; Wilhelm, H. M.; Ramos, L. P.; J. Braz. Chem. Soc. 2007, 18, 416.

4. Tang, H.; Wang, A.; Salley, S. O.; Ng, K. Y. S.; J. Am. Oil Chem. Soc. 2008, 85, 373.

5. Das, L. M.; Bora, D. K.; Pradhan, S.; Naik, M. K.; Naik, S. N.; Fuel 2009, 88, 2315.

6. Tang, H.; De Guzman, R. C.; Ng, K. Y. S.; Salley, S. O.; Energy Fuels 2010, 24, 2028.

7. Rizwanul-Fattah, I. M.; Masjuki, H. H.; Kalam, M. A.; Hazrat, M. A.; Masum, B. M.; Imtenan, S.; Ashraful, A. M.; Renewable Sustainable Energy Rev. 2014, 30, 356.

8. Santos, A. L.; Takeuchi, R. M.; Muñoz, R. A. A.; Angnes, L.; Stradiotto, N. R.; Electroanalysis 2014, 26, 233.

9. Notsu, H.; Tatsuma, T.; J. Electroanal. Chem. 2004, 566, 379.

10. Araujo, A. S. A.; Caramit, R. P.; Oliveira, L. C. S.; Ferreira, V. S.; Electroanalysis 2015, 27, 1152.

11. Feng, P.-S.; Wang, S.-M.; Su, W.-Y.; Cheng, S.-H.; J. Chin. Chem. Soc. 2012, 59, 231.

12. Tashkhourian, J.; Ghaderizadeh, S. M.; Russ. J. Electrochem. 2014, 50, 959.

13. Bao, A.; Xiao, N.; Zhu, Y.; Xin, S.; Zhang, H.; RSC Adv. 2015, 5,12710 .

14. Badawy, W. A.; Ismail, K. M.; Medany, S. S.; Int. J. Electrochem. 2011, 6, 4204.

15. Santos, A. L.; Takeuchi, R. M.; Muñoz, R. A. A.; Angnes, L.; Stradiotto, N. R.; Electroanalysis 2012, 24, 1681.

16. Tormin, T. F.; Gimenes, D. T.; Silva, L. G.; Ruggiero, R.; Richter, E. M.; Ferreira, V. S.; Muñoz, R. A. A.; Talanta 2010, $82,1599$.

17. Almeida, E. S.; Richter, E. M.; Munoz, R. A. A.; Anal. Chim. Acta 2014, 837, 38.

18. Wildgoose, G. G.; Banks, C. E.; Leventis, H. C.; Compton, R. G.; Microchim. Acta 2006, 152, 187.

19. Pumera, M.; Chem. Rec. 2012, 12, 201.

20. Agüí, L.; Yáñez-Sedeño, P.; Pingarrón, J. M.; Anal. Chim. Acta 2008, 622, 11.
21. Banks, C. E.; Moore, R. R.; Davies, T. J.; Compton, R. G.; Chem. Comm. 2004, 1804.

22. Ji, X.; Kadara, R. O.; Krussma, J.; Chen, Q.; Banks, C. E.; Electroanalysis 2010, 22, 7.

23. Wang, L.; Pumera, M.; Chem. Comm. 2014, 50, 12662.

24. Henstridge, M. C.; Dickinson, E. J. F.; Aslanoglu, M.; BatchelorMcAuley, C.; Compton, R. G.; Sens. Actuators, B 2010, 145, 417.

25. Ziyatdinova, G.; Gainetdinova, A.; Morozov, M.; Budnikov, H.; Grazhulene, S.; Red'kin, A.; J. Solid State Electrochem. 2012, 16, 127.

26. Pedrotti, J. J.; Angnes, L.; Gutz, I. G. R.; Electroanalysis 1996, $8,673$.

27. Vuković, G.; Marinković, A.; Obradović, M.; Radmilović, V.; Čolić, M.; Aleksić, R.; Uskoković, P. S.; Appl. Surf. Sci. 2009, 255, 8067.

28. Silva, R. A. B.; Montes, R. H. O.; Richter, E. M.; Munoz, R. A. A.; Food Chem. 2012, 133, 200.

29. Cardoso, R. M.; Montes, R. H. O.; Lima, A. P.; Dornellas, R. M.; Nossol, E.; Richter, E. M.; Munoz, R. A. A.; Electrochim. Acta 2015, 176, 36.

30. Gazotti, W. A.; Matencio, T.; De Paoli, M.-A.; Electrochim. Acta 1998, 43, 457.

31. Zhao, C.; Song, J.; Zhang, J.; Talanta 2003, 59, 19.

32. Montes, R. H. O.; Dornellas, R. M.; Silva, L. A. J.; Squissato, A. L.; Richter, E. M.; Munoz, R. A. A.; J. Solid State Electrochem. 2016, 20, 2453.

33. Dornellas, R. M.; Tormin, T. F.; Richter, E. M.; Aucélio, R. Q.; Munoz, R. A. A.; Anal. Lett. 2014, 47, 492.

34. Almeida, E. S.; Monteiro, M. A. N. A.; Montes, R. H. O.; Mosquetta, R.; Coelho, N. M. M.; Richter, E. M.; Muñoz, R. A. A.; Electroanalysis 2010, 22, 1846.

Submitted: October 5, 2016

Published online: December 7, 2016 